\title{
Age, Cognitive Factors, and Acceptance of Living with the Disease in Rheumatoid Arthritis: The Short-Term Perspective
}

\author{
Daniel Pankowski ${ }^{1,2, *}$, Kinga Wytrychiewicz-Pankowska ${ }^{1,2}$, Ewa Pisula ${ }^{1}$, Andrzej Fal ${ }^{3,4}{ }^{\circledR}$, Bartłomiej Kisiel ${ }^{5}$, \\ Ewa Kamińska ${ }^{6}$ and Witold Tłustochowicz ${ }^{7}$ (i)
}

Citation: Pankowski, D.; Wytrychiewicz-Pankowska, K.;

Pisula, E.; Fal, A.; Kisiel, B.;

Kamińska, E.; Tłustochowicz, W. Age Cognitive Factors, and Acceptance of

Living with the Disease in

Rheumatoid Arthritis: The

Short-Term Perspective. Int. J.

Environ. Res. Public Health 2022, 19,

3136. https://doi.org/10.3390/

ijerph19053136

Academic Editor: Hajime Iwasa

Received: 30 January 2022

Accepted: 28 February 2022

Published: 7 March 2022

Publisher's Note: MDPI stays neutral with regard to jurisdictional claims in published maps and institutional affiliations.

Copyright: (C) 2022 by the authors Licensee MDPI, Basel, Switzerland. This article is an open access article distributed under the terms and conditions of the Creative Commons Attribution (CC BY) license (https:// creativecommons.org/licenses/by/ $4.0 /)$.
1 Department of Health and Rehabilitation Psychology, Faculty of Psychology, University of Warsaw, 00-927 Warsaw, Poland; kwytrychiewicz@gmail.com (K.W.-P.); ewa.pisula@psych.uw.edu.pl (E.P.)

2 Institute of Psychology, University of Economics and Human Sciences in Warsaw, 01-043 Warsaw, Poland

3 Department of Public Health, Medical University of Wrocław, 51-618 Wrocław, Poland; amfal@wp.pl

4 Warsaw Faculty of Medicine, Collegium Medicum, Cardinal Stefan Wyszyński University, 01-938 Warsaw, Poland

5 Clinical Research Support Center, Military Institute of Medicine in Warsaw, 04-141 Warsaw, Poland; bkisiel@wim.mil.pl

6 Department of Rheumatology, Provincial Integrated Hospital in Płock, 09-400 Płock, Poland; awezuzia@mp.pl

7 Department of Internal Diseases and Rheumatology, Military Institute of Medicine, 04-141 Warsaw, Poland; wtlustochowicz@wim.mil.pl

* Correspondence: daniel.pankowski@psych.uw.edu.pl

\begin{abstract}
Rheumatoid arthritis is a chronic inflammatory disease leading to disability, reduced quality of life, and severe depressive symptoms. Theoretical models and research emphasize the importance of cognitive factors such as illness-related beliefs and cognitive appraisals in the process of adapting to life with a chronic disease. Objectives: The aim of this study was to analyze the role of age, disease duration, and cognitive factors in the level of acceptance of life with rheumatoid arthritis and determine the factors responsible for short-term (one week) changes without the use of interventions. We also assessed differences in predictors between rheumatoid arthritis, vascular diseases, and diabetes. Methods: Data were collected using a panel study. The first part of the analysis included 83 participants who declared a medical diagnosis of rheumatoid arthritis. In the second part of the analysis, in addition to people with rheumatoid arthritis (69 participants), two control groups were also included: diabetes $(n=26)$ and vascular disease $(n=26)$. The analysis examined basic sociodemographic and clinical data, cognitive appraisals, illness-related beliefs, and acceptance of living with the disease twice in one week. Results: The relationship between age and levels of acceptance of living with the disease was cubic, but the groups distinguished based on age and disease duration did not differ in terms of the analyzed variables. Cognitive appraisals (both baseline and changes over one week) were responsible for changes in acceptance of living with the disease, although other variables (sociodemographic, clinical, and illness-related beliefs) also played a role. The predictors of change in acceptance of living with the disease differed between analyzed diagnoses. Conclusions: Cognitive factors are an important aspect of the adaptation process to living with an illness. Potential clinical applications and future directions of research are discussed.
\end{abstract}

Keywords: acceptance; rheumatoid arthritis; vascular diseases; diabetes; longitudinal study

\section{Introduction}

The growing number of people struggling with chronic diseases is a serious global issue [1]. Epidemiological data show that these types of problems affect not only the elderly, but also young people, resulting in, for example, negative impacts on their ability to perform paid work, fulfill social roles, and quality of life [2]. These types of difficulties may additionally increase the risk of other disorders, particularly mental health issues such as depression $[3,4]$. For this reason, it is extremely important to study factors, both 
modifiable (such as psychological factors) and non-modifiable (such as age), that can help chronically ill people adapt and reduce their burden.

Adapting to life with a chronic disease is a long and complicated process. The extent to which a person adjusts to living with a disease is most often described by positive (e.g., acceptance of living with the disease; ALD) and negative (severity of depressive or anxiety symptoms) indicators [5], and these indicators are of great importance for a patient's quality of life [6,7] and adherence to medical regimens [8]. It is worth emphasizing that a high degree of adaptation is not constituted by a lack of depressive or anxiety symptoms, but should also be characterized by high levels of positive indicators, such as ALD.

Levels of ALD have been analyzed in many groups of patients. In patients with chronic heart failure, it has been observed that reduced health-related quality of life may contribute to difficulties accepting the disease, which, in turn, result in diminished involvement of the patient in the treatment process [9]. Similar conclusions were drawn by Bien et al. [10] in the context of pregnant diabetes patients: their results indicated that higher ALD contributes to a better quality of life and perception of health. Research conducted with elderly people indicated that patients' depression symptoms and functional and cognitive status are correlates of ALD [11]. In turn, in a study conducted on a group of diabetic patients, Bak et al. [12] noticed that sexual dysfunction is related to level of acceptance of the disease. On the other hand, Janowski et al. [13] noted that in patients with lower back pain, the appraisals of the disease, such as obstacle, threat, or illness importance, play a very important role in ALD. However, to date, few studies have investigated factors related to ALD levels in people with RA and its cognitive correlates [14].

Rheumatoid arthritis (RA) is a chronic inflammatory disease that affects approximately $1 \%$ of the population and is much more common in women than in men. The most common symptoms of RA are pain, morning stiffness, and swollen joints [15]. The course of RA varies over time and between individuals. Scott and Steer [16] identify three indicators to define the course of RA: the impact of joint inflammation, the effect of RA on general health, and its effect on joint damage. The disease is progressive, with increasing difficulties in daily functioning [17], leading over time to disability. Numerous studies indicate, inter alia, a reduced level of quality of life [18] and a high intensity of depression and anxiety symptoms [19]. In addition to clinical factors that may contribute to the deterioration of the indicators of adaptation to the disease [20], psychological variables also play an important role, including beliefs related to the disease [21], self-efficacy, and social support [22]. However, as noted earlier, little attention has been paid to the study of ALD in this group of patients. Kostove et al. [23], on the basis of interviews conducted with a group of 20 people with RA, distinguished five periods of acceptance of living with the disease (naming the illness, realizing the illness, resisting the illness, 'hitting the bottom', and integrating the illness), while pointing out that acceptance of living with illness is not a linear process in this group of patients. In turn, Paloș and Vîscu [14] observed that unconditional selfacceptance is negatively correlated with both psychological and somatic anxiety as well as with automatic negative thoughts. In further research, it is worth considering factors that would be susceptible to modification by various types of interventions.

The coping with disease model of Maes, Leventhal, and de Ridder [24] and the common-sense model of illness (CSM; Leventhal et al. [25]) are frequently used to analyze this process of adaptation. Both of these approaches attribute significant roles to cognitive factors: cognitive appraisals (CAs) and cognitive representations of the disease/illnessrelated beliefs (IRBs), respectively. According to Lazarus and Folkman's [26] stress-coping theory, a person's relationship to their environment is subject to CA, which addresses elements of the situation that are relevant to the individual's well-being. In the context of chronic illness, CAs are of critical importance in determining both the emotions experienced and the choice of strategies used to cope with illness-related stress [24]. On the other hand, the CSM of illness elaborates on what illness representations consist of, while providing a conceptual framework that explores the perceptual, behavioral, and cognitive processes that influence health behavior and coping outcomes [27]. In this theoretical framework, IRBs 
are postulated to cover five key components of a disease: (1) an identity component; (2) a causal component; (3) a time component; (4) a consequence component; and (5) a disease treatment/controllability component $[25,28]$. The most important difference between these constructs is that CAs are cognitive processes while IRBs provide a cognitive structure.

Previous research has shown that IRBs can change over time and are related to mental health [29], while CAs are associated with the effects of the adaptation process (see: [26]) and clinical factors [24]. As mentioned above, adaptation to a chronic disease is a dynamic process, therefore both its indicators and individual components change over time. In addition to non-modifiable variables such as age or gender, theoretical models distinguish a number of factors that may be the subject of therapeutic work. The vast majority of studies focus on assessing the effectiveness of selected interventions in the short term (immediately after it ends) and long term (e.g., 6 months later; [30]). However, little is known about how the adaptation process proceeds; in particular, about the changes that may occur in IRBs or CAs attributed to the disease in the short term, without the use of therapeutic interventions. There is still not enough data in the literature on this subject. This gap could be filled by an in-depth analysis of so-called "waiting list" groups, but in the literature they are only treated as a reference point for the experimental and placebo groups. Similarly, also in a short-term perspective, statistically significant changes in the scope of constructs, which are often described as stable over time, cannot be expected, which may additionally contribute to the failure of previous studies to address this issue. IRBs may change over time [31] and depend on the information received by patients (e.g., via social media or contact with other patients) and whether they can be modified; thus, the formation of beliefs is dynamic. Cognitive appraisals of diseases may also change over time, being sensitive to changes in the patient's clinical condition, coping strategies used, assessment of one's resources, previous adaptation effects, etc. [24]. Due to this fact, it should be assumed that cognitive factors can influence the level of adaptation over the course of days or weeks, independent of any intervention. Such changes may suggest directions for interventions for patients, particularly informational/educational interventions. This is particularly important in countries or regions where access to psychological care is difficult for people suffering from chronic diseases.

Taking into account all the above information, the study adopted four research objectives:

- Research objective 1: Describe the relationship between age, duration of the disease, and levels of ALD in RA patients.

- $\quad$ Research objective 2: Describe the relationships between modifiable cognitive variables and levels of ALD.

- $\quad$ Research objective 3: Assess the stability of IRBs and CAs in the short term.

- $\quad$ Research objective 4: Identify ALD predictors in RA in the short-term perspective and compare them between different medical diagnoses.

\section{Method}

\subsection{Participants and Procedure}

Due to the pandemic and the resulting difficulties faced by health services, the data were collected using a panel study and repeated measurements were taken between the 23 February 2021 (T1) and 03 March 2021 (T2). Inclusion criteria were: a declared medical diagnosis of rheumatoid arthritis (RA), vascular diseases (VD), or diabetes (D); being aged above 18 years; declaring the absence of mental disorders (e.g., depression); and having no oncological diseases. In the case of comorbidities, participants were asked to take into account only the above-mentioned diseases in their responses. The purpose of the study was blinded and all participants gave informed consent. The study was approved by the Local Ethics Board.

The first measurement was performed on a sample of 83 participants declaring a medical diagnosis of RA; it included 35 men (42.2\%) and 48 women (57.8\%). The mean age of the respondents was $59.66(\mathrm{SD}=13.58)$ and the mean duration of illness was 11.20 $(\mathrm{SD}=8.89)$. 
Repeated measurement was performed on a total of 121 people: 69 RA participants and 2 control groups-vascular diseases $(V D ; n=26)$ and diabetes $(D ; n=26)$. The choice of these diseases was based on their high prevalence in the general population, diverse age at disease onset, as well as a similar gender prevalence. The study sample was $41.3 \%$ women (RA: 53.6\%; VD: 34.6\%; D: 15.4\%) and the mean age was 60.66 (SD = 14.6) years-RA: 58.91 (SD = 13.75); VD: 62.65 (SD = 13.88); D: 63.31 (SD = 15.34). The mean duration of the disease in the analyzed sample was $12.4(\mathrm{SD}=9.84)$ years-RA: $11.07(\mathrm{SD}=8.19)$; VD: 17.42 (SD = 13.68); $\mathrm{D}: 10.88$ (SD = 7.81). The mean number of hospitalizations during the last 12 months was $0.34(\mathrm{SD}=0.80)$-RA: $0.054(\mathrm{SD}=0.98)$; VD: $0.12(\mathrm{SD}=0.43)$; D: 0.04 $(\mathrm{SD}=0.20)$.

\subsection{Questionnaires}

Sociodemographic Variables: Gender (Male/Female/Other); Age in Years

Clinical variables: Time since diagnosis of the disease (in years); number of hospitalizations in the last 12 months.

The Illness-Related Beliefs Questionnaire (IRBQ; [32]; Supplementary File S1) was used to assess the intensity of the patient's personal beliefs about key aspects of their chronic disease. Thirteen IRBs were assessed on a continuum ranging from 1 to 10 .

Illness-Related Appraisals Scale-Revised [33]; Supplementary File S2): this self-report scale assesses the following appraisals: loss (T1 $\alpha=0.92 ; \mathrm{T} 2 \alpha=0.93)$, harm (T1 $\alpha=0.93$; T2 $\alpha=0.94$ ), benefit (T1 $\alpha=0.85$; T2 $\alpha=0.92)$, challenge (T1 $\alpha=0.89$; T2 $\alpha=0.92)$, value (T1 $\alpha=0.87$; T2 $\alpha=0.90)$, threat (T1 $\alpha=0.90$; T2 $\alpha=0.95)$, and importance (T1 $\alpha=0.86$; T2 $\alpha=0.84)$.

The Acceptance of Life with the Disease Scale (ALDS; [34]) was used to measure the degree of acceptance of one's life with a disease. It consists of three subscales: satisfaction with life despite the disease (T1 $\alpha=0.87 ; \mathrm{T} 2 \alpha=0.87)$; reconcilement with the disease (T1 $\alpha=0.87$; T2 $\alpha=0.88$ ); self-distancing from the disease (T1 $\alpha=0.84$; T2 $\alpha=0.90$ ); and global score (T1 $\alpha=0.93 ; \mathrm{T} 2 \alpha=0.93)$.

\subsection{Statistical Analysis}

First, outliers were assessed in terms of age using box plots. The next step was to determine the relationship between age and ALD using curve estimation in RA patients.

In the next step, the confirmatory factor analysis (CFA) of the scales used in the crosssectional study was performed. This allowed the derivation of the statistically strongest weighting combination of the individual variables in each category to form a latent variable in structural equation modeling (SEM). Confirmatory factor analytic models were applied and tested in a stepwise manner for each of the five latent variables separately. First, individual parameters within each of the construct models (e.g., factor loadings) were evaluated for significance at the $p<0.05$ level. Minor adjustments were applied to the models to arrive at a final factor structure for each of the analyzed constructs.

Subsequently, SEM was carried out using the latent variables identified in the first step. The overall objective of the modeling was to develop a relatively parsimonious representation of the information that would maximize the model fit while judiciously utilizing available degrees of freedom. The IBM AMOS 27 program was used in the calculations.

The next step was to assess the significance of differences between T1 and T2 in terms of IRBs, CA, and ALD both in the whole group and in the subgroups distinguished by diagnosis. For this purpose, the $t$-test for dependent samples was used. Further, the interactions between predictors of ALD were calculated using the "jtools" R package [35]. The next step was to determine the predictors of changes in ALD. In order to do so, stepwise regression analyses were performed in which the dependent variables were T2-T1 differences in ALDS global score and subscales. Sociodemographic and clinical variables, CAs (T1), IRBs (T1), and changes in CAs (T2-T1) and IRBs (T2-T1) were analyzed as factors that may be responsible for changes in ALD. Reliability was assessed using Cronbach's alpha. The analyses were performed with SPSS 27.0.1.0 and RStudio. 


\section{Results}

First, the relationship between age and ALD was explored using curve estimation (Figure 1).

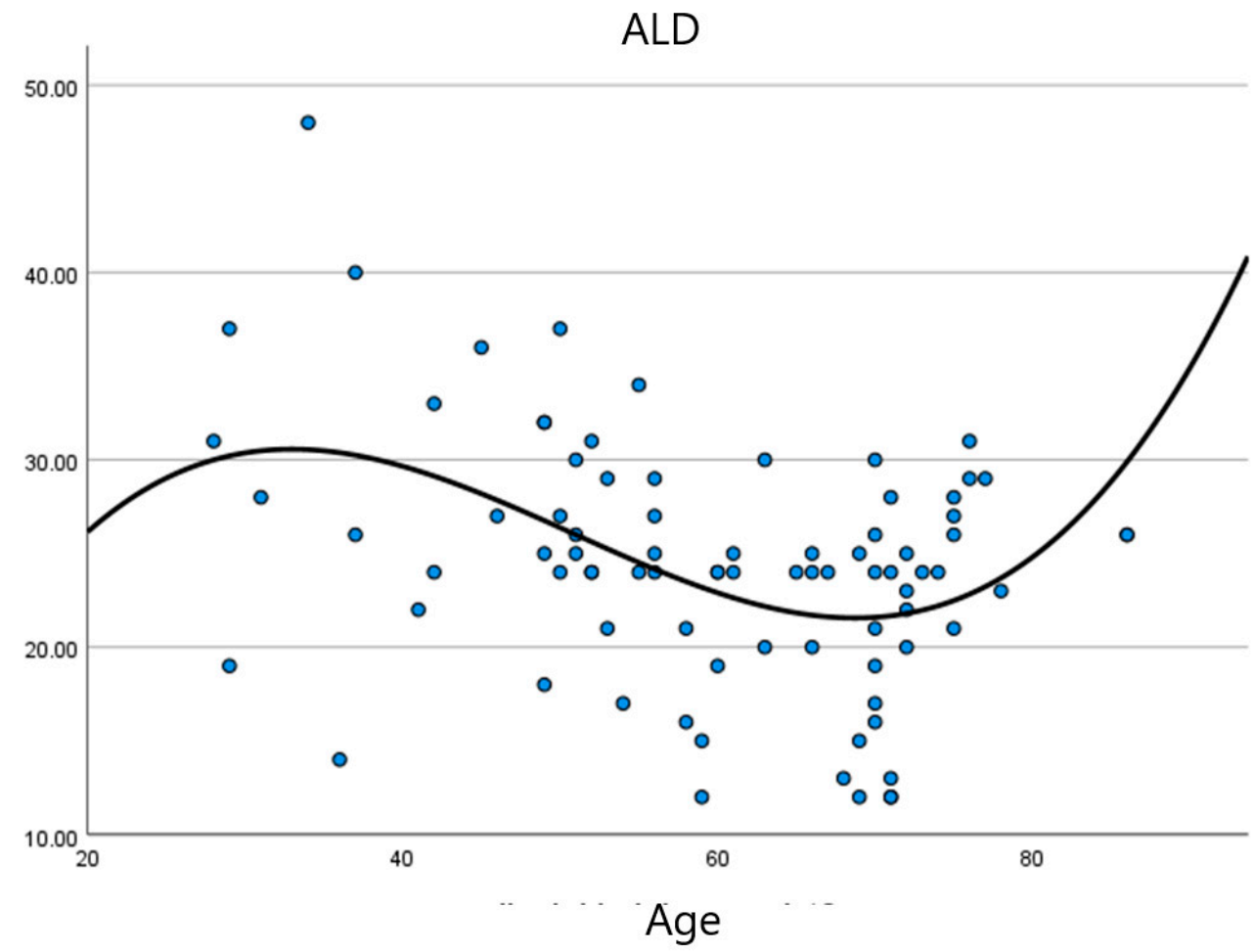

Figure 1. Relationship between ALD and age. ALD—Acceptance of living with the disease.

To analyze the relationship between ALD and age, curve estimation was used, which showed that the most accurate model was the cubic model $\left(R^{2}=0.20 ; \mathrm{F}(3.79)=6.72\right.$; $p<0.001)$. Further analyses showed no relationship between the duration of illness and the level of ALD, and again the cubic model turned out to be the best fitted model $\left(R^{2}=0.03\right.$; $\mathrm{F}(3.79)=0.77 ; p>0.05)$.

The models used to separately develop the constructs representing IRBs (subscales: disease, control, and social), CAs, and ALD all resulted in a satisfactory fit to the observed correlations (see Table 1).

Table 1. Confirmatory factor analytic results for the development of latent variables.

\begin{tabular}{ccccccc}
\hline Latent Variable & $\chi^{2}$ & $p$ & GFI & CFI & TLI & RMSEA \\
\hline IRB-Disease & 0.86 & $>0.05$ & 0.995 & 1000 & 1.038 & 0.000 \\
\hline IRB-Social & 4.587 & $>0.05$ & 0.975 & 0.934 & 0.803 & 0.126 \\
\hline IRB-Control & 3.939 & $>0.05$ & 0.982 & 1000 & 1.426 & 0.000 \\
\hline CA & 1.102 & $>0.05$ & 0.995 & 1000 & 1.032 & 0.000 \\
\hline $\begin{array}{c}\text { ALD- } \\
\text { Reconcilement }\end{array}$ & 3.228 & $>0.05$ & 0.982 & 0.993 & 0.979 & 0.087 \\
\hline $\begin{array}{c}\text { ALD- } \\
\text { Satisfaction }\end{array}$ & 0.502 & $>0.05$ & 0.997 & 1000 & 1.024 & 0.000 \\
\hline $\begin{array}{c}\text { ALD-Self- } \\
\text { distancing }\end{array}$ & 1.741 & $>0.05$ & 0.989 & 1000 & 1.005 & 0.000 \\
\hline
\end{tabular}

Table 2 shows the standardized factor loadings for each of the analyzed variables (see also Supplementary Files S3-S8). 
Table 2. Standardized factor loadings for all latent variables.

\begin{tabular}{|c|c|c|c|c|c|c|c|}
\hline & IRB-Disease & IRB-Control & IRB-Social & CA & $\begin{array}{c}\text { ALD- } \\
\text { Satisfaction }\end{array}$ & $\begin{array}{c}\text { ALD- } \\
\text { Reconcilement }\end{array}$ & $\begin{array}{c}\text { ALD- } \\
\text { Distancing }\end{array}$ \\
\hline IRB 1 & 0.58 & & & & & & \\
\hline IRB 2 & 0.77 & & & & & & \\
\hline IRB 3 & 0.83 & & & & & & \\
\hline IRB 5 & 0.58 & & & & & & \\
\hline IRB 6 & & -0.02 & & & & & \\
\hline IRB 7 & & 0.26 & & & & & \\
\hline IRB 8 & & 0.25 & & & & & \\
\hline IRB 9 & & 0.6 & & & & & \\
\hline IRB 10 & & 0.44 & & & & & \\
\hline IRB 4 & & & 0.55 & & & & \\
\hline IRB 11 & & & 0.56 & & & & \\
\hline IRB 12 & & & 0.53 & & & & \\
\hline IRB 13 & & & 0.64 & & & & \\
\hline CA: Loss & & & & 0.91 & & & \\
\hline CA: Harm & & & & 0.75 & & & \\
\hline \multicolumn{2}{|c|}{ CA: Challenge } & & & 0.67 & & & \\
\hline \multicolumn{2}{|c|}{ CA: Threat } & & & 0.92 & & & \\
\hline \multicolumn{2}{|c|}{ CA: Importance } & & & 0.68 & & & \\
\hline ALD 1 & & & & & 0.86 & & \\
\hline ALD 5 & & & & & 0.85 & & \\
\hline ALD 8 & & & & & 0.89 & & \\
\hline ALD 10 & & & & & 0.68 & & \\
\hline ALD 2 & & & & & & 0.81 & \\
\hline ALD 3 & & & & & & 0.82 & \\
\hline ALD 6 & & & & & & 0.84 & \\
\hline ALD 9 & & & & & & 0.78 & \\
\hline ALD 4 & & & & & & & 0.78 \\
\hline ALD 7 & & & & & & & 0.85 \\
\hline ALD 11 & & & & & & & 0.78 \\
\hline ALD 12 & & & & & & & 0.75 \\
\hline
\end{tabular}

Three IRB factors were distinguished: IRB-Disease, IRB-Control, and IRB-Social. In the case of IRB-Control, despite the good model fit parameters, the factor loading remained statistically insignificant, so this latent variable was not included in the analyses. On the other hand, in the case of CA, two assessments-value and benefit-were removed from the model to improve its fit. In the case of ALD, three factors were used in accordance with the original assumptions of the scale, which were then placed in the models as explained variables.

For each of the models, the solutions were assessed and a number of solutions were tested, first using the significance level of regression weights and then the model fit parameters. A number of models were tested to assess both the direct and indirect (via CA) influence of IRBs (Disease and Social) on levels of ALD. The best fit models are shown below (Figures 2-4). The model fit parameters are presented in Table 3.

Table 3. Summary of the models and associated goodness-of-fit indices.

\begin{tabular}{ccccccccc}
\hline ALD Subscales & $\chi^{2}$ & df & $p$ & Normed $\chi^{2}$ Value & CFI & TLI & AIC & BIC \\
\hline ALD-Reconcilement & 198.769 & 114 & $<0.001$ & 1.744 & 0.877 & 0.854 & 276.769 & 371.103 \\
\hline ALD-Satisfaction & 186.682 & 114 & $<0.001$ & 1.638 & 0.896 & 0.876 & 264.682 & 359.017 \\
\hline ALD-Distancing & 177.89 & 114 & $<0.001$ & 1.56 & 0.903 & 0.884 & 255.89 & 350.225 \\
\hline
\end{tabular}




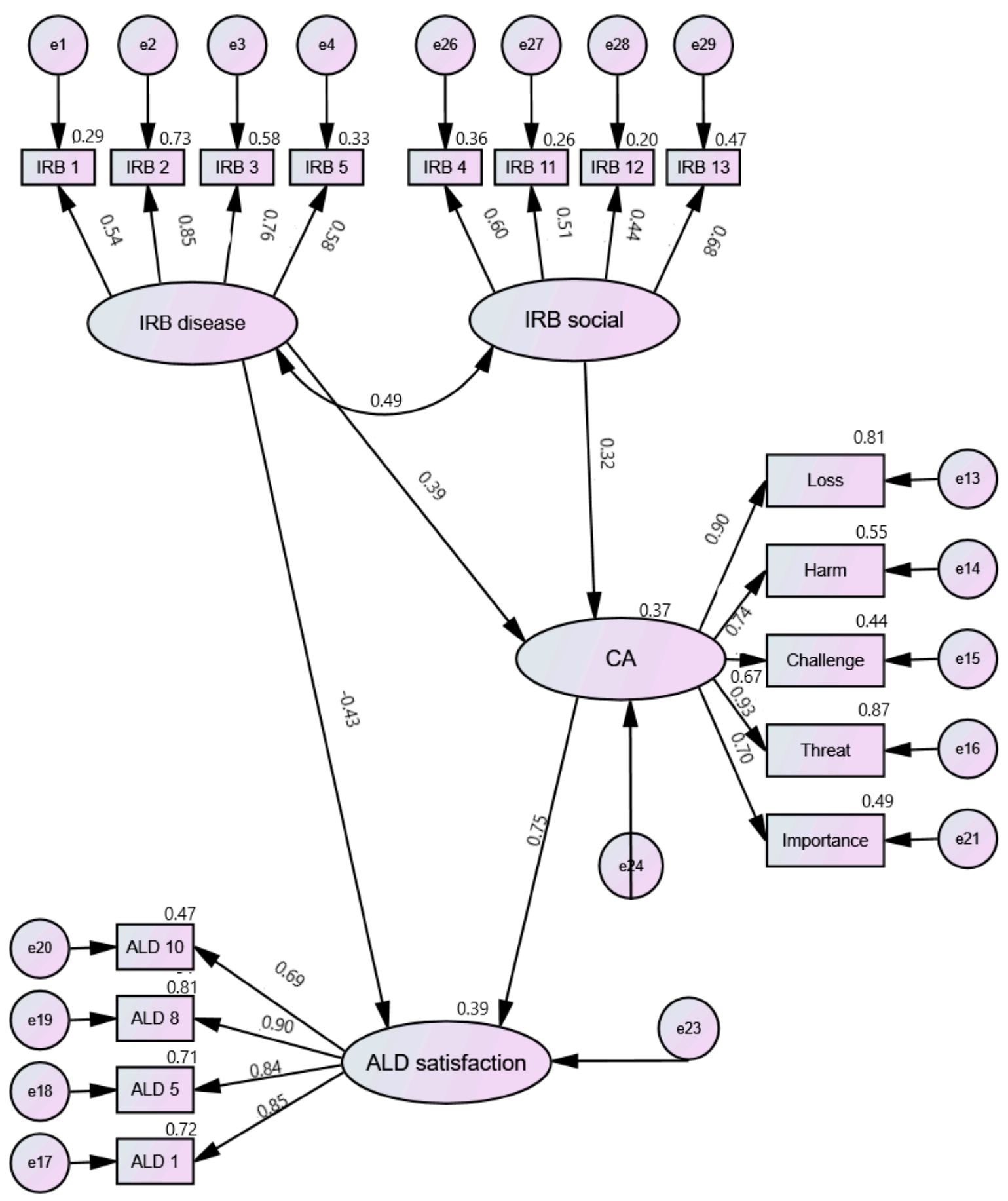

Figure 2. Cognitive factors and ALD Satisfaction: Path diagram. IRB-Illness-related Beliefs; CACognitive Appraisal; ALD—Acceptance of Living with the Disease. 


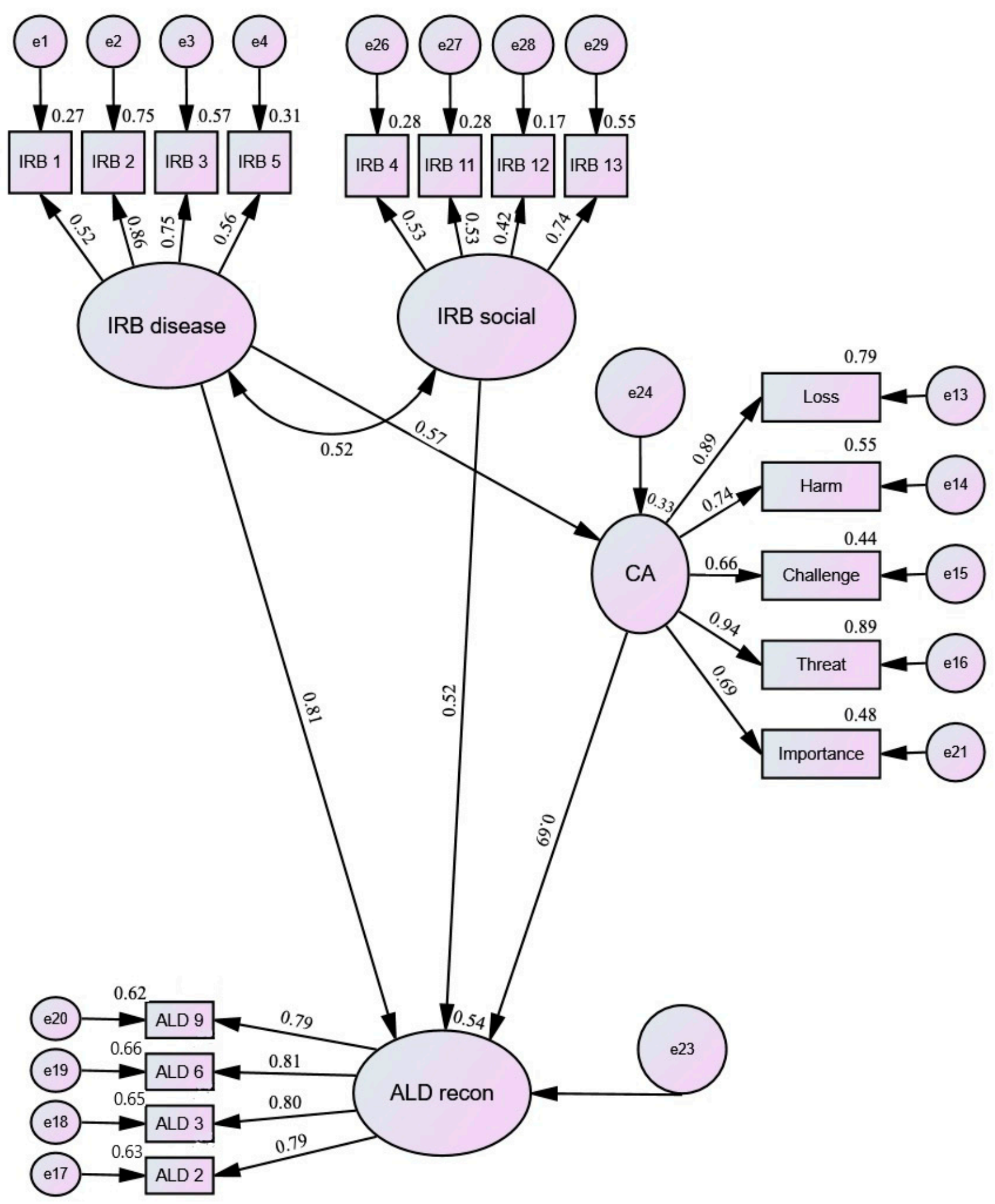

Figure 3. Cognitive factors and ALD Reconcilement: Path diagram. IRB-Illness-related Beliefs; CA-Cognitive Appraisal; ALD recon-Acceptance of Living with the Disease: Reconcilement. 


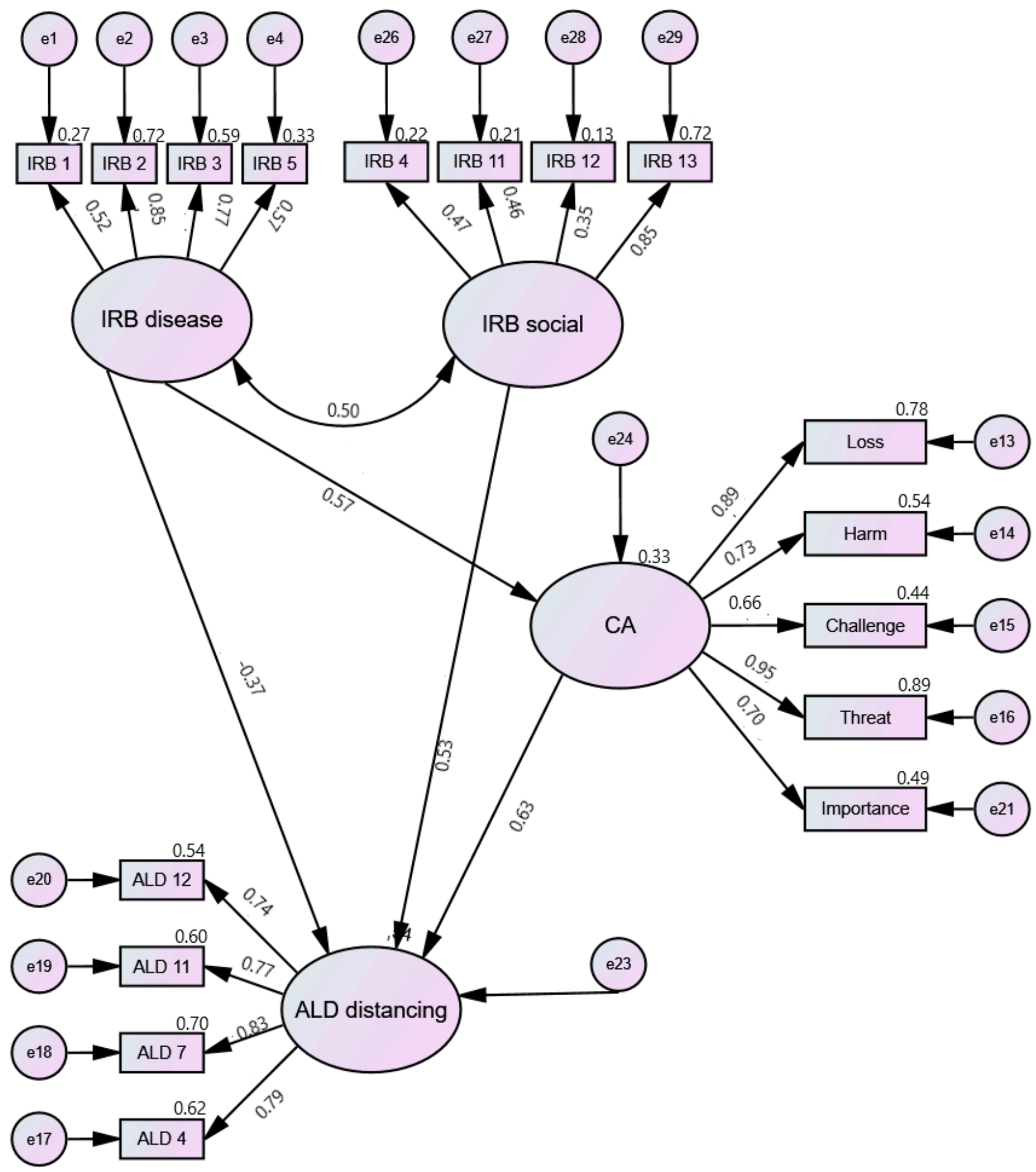

Figure 4. Cognitive factors and ALD Distancing: Path diagram. IRB—Illness-related Beliefs; CACognitive Appraisal; ALD-Acceptance of Living with the Disease.

Reconcilement and Distancing had the same path pattern: IRB-Disease had both direct and indirect (via CA) effects on these ALD components; IRB-Social and CA had direct effects on ALD. For ALD-Satisfaction, the best model was that in which IRB-Disease had both direct and indirect (via CA) effects on ALD; IRB-Social had an indirect effect (via CA) on ALD.

T2-T1 correlations between the analyzed variables are presented in Supplementary File S9. The analysis of the repeated measurement data began with a comparison of the mean IRBs, CAs, and ALDs between measurements 1 and 2 (Table 4). 
Table 4. Differences between T1 and T2.

\begin{tabular}{|c|c|c|c|c|c|c|c|}
\hline \multirow{2}{*}{ Variables } & \multicolumn{2}{|c|}{ T1 } & \multicolumn{2}{|c|}{ T2 } & \multirow{2}{*}{$t$} & \multirow{2}{*}{$p$} & \multirow{2}{*}{ Cohen's } \\
\hline & $\mathbf{M}$ & SD & $\mathbf{M}$ & SD & & & \\
\hline IRB 1 & 8.76 & 1.65 & 8.32 & 2.03 & 2.137 & 0.035 & 0.194 \\
\hline IRB 2 & 7.83 & 1.97 & 7.54 & 2.15 & 1.424 & 0.157 & 0.129 \\
\hline IRB 3 & 7.36 & 2.06 & 7.06 & 2.18 & 1.700 & 0.092 & 0.155 \\
\hline IRB 4 & 4.76 & 2.70 & 4.58 & 2.81 & 0.800 & 0.425 & 0.073 \\
\hline IRB 5 & 6.40 & 2.42 & 6.39 & 2.47 & 0.079 & 0.937 & 0.007 \\
\hline IRB 6 & 7.83 & 1.75 & 7.93 & 1.81 & -0.696 & 0.488 & -0.063 \\
\hline IRB 7 & 4.34 & 2.86 & 4.69 & 2.76 & -1.772 & 0.079 & -0.161 \\
\hline IRB 8 & 5.07 & 2.69 & 5.06 & 2.74 & 0.061 & 0.952 & 0.006 \\
\hline IRB 9 & 5.34 & 2.66 & 5.12 & 2.52 & 0.880 & 0.380 & 0.080 \\
\hline IRB 10 & 4.88 & 2.29 & 5.07 & 2.30 & -0.745 & 0.458 & -0.068 \\
\hline IRB 11 & 3.82 & 2.28 & 4.09 & 2.44 & -1.328 & 0.187 & -0.121 \\
\hline IRB 12 & 2.69 & 2.43 & 3.12 & 2.77 & -2.298 & 0.023 & -0.209 \\
\hline IRB 13 & 4.31 & 2.47 & 4.53 & 2.38 & -1.036 & 0.302 & -0.094 \\
\hline Loss & 14.31 & 5.09 & 13.95 & 5.25 & 1.060 & 0.291 & 0.096 \\
\hline Harm & 12.06 & 5.09 & 12.03 & 5.43 & 0.077 & 0.938 & 0.007 \\
\hline Benefit & 7.79 & 3.15 & 8.55 & 4.16 & -2.577 & 0.011 & -0.234 \\
\hline Challenge & 16.01 & 4.57 & 15.55 & 4.71 & 1.433 & 0.154 & 0.130 \\
\hline Value & 13.35 & 4.51 & 13.64 & 4.66 & -1.025 & 0.308 & -0.093 \\
\hline Threat & 15.56 & 4.25 & 14.88 & 4.93 & 2.134 & 0.035 & 0.194 \\
\hline Importance & 16.07 & 4.27 & 15.93 & 4.59 & 0.381 & 0.704 & 0.035 \\
\hline ALD-Satisfaction & 7.88 & 2.25 & 8.12 & 2.38 & -1.745 & 0.084 & -0.159 \\
\hline ALD-Reconcilement & 6.99 & 1.88 & 7.06 & 1.92 & -0.487 & 0.627 & -0.044 \\
\hline ALD-Distancing & 8.75 & 2.35 & 9.04 & 2.72 & -1.434 & 0.154 & -0.130 \\
\hline ALD Global Score & 23.63 & 5.77 & 24.22 & 6.20 & -1.517 & 0.132 & -0.138 \\
\hline
\end{tabular}

The analyses showed that there were statistically significant differences between T1 and T2 in terms of IRB1 (relating to the duration of the disease), IRB12 (relating to embarrassment), and benefit (CA). On the other hand, the analyses carried out in the subgroups distinguished according to diagnosis showed that for people with diabetes, a statistically significant difference in IRB 1 (reduction at T2) and ALD-Satisfaction (increase at T2) was observed. In people with RA, statistically significant differences were found in IRB 4 (relating to the visibility of symptoms; decrease at T2) and IRB 12 (increase at T2). There were no statistically significant differences in the VD group (see Supplementary File S10 for details). However, it should also be noted that the analyzed groups were small, so the differences might not be statistically significant.

In the next step, interactions between consecutive ALDS predictors (global score and subscales) and medical conditions were analyzed. The results (see Supplementary Files S11-S15) showed statistically significant interactions between IRBs regarding one's condition improving (T1 and T2-T1), visibility of symptoms (T1), the possibility of predicting the course of the disease (T1), the possibility of obtaining help from medical personnel (T1), how embarrassing the disease is (T1), the effectiveness of treatment (T2-T1), the attitude of other people to people with this disease (T2-T1), the belief regarding the comparison of disease severity with other people (T2-T1), as well as the following CAs: harm (T1 and T2-T1), importance (T1 and T2-T1), challenge (T2-T1), threat (T2-T1), age, and hospitalizations. 
In the next step, stepwise regression was computed with changes in ALDS global score and subscales as dependent variables. As independent variables, sociodemographic and clinical variables (T1) as well as cognitive variables (CAs and IRBs) — both baseline values (T1) and differences between T2 and T1-were introduced into the models (Table 5).

Table 5. Predictors of changes in Acceptance of Living with the Disease.

\begin{tabular}{|c|c|c|c|c|c|c|}
\hline & Statistically Significant Predictors & $\begin{array}{l}R^{2} \text { for the } \\
\text { Model }\end{array}$ & $\begin{array}{l}\text { Adjusted } R^{2} \text { for } \\
\text { the Model }\end{array}$ & $\beta$ & $t$ & $p$ \\
\hline \multicolumn{7}{|c|}{ Acceptance: Global score } \\
\hline \multirow{3}{*}{$\begin{array}{c}\text { All: }(B=0.943 ; F=7.465 \\
\quad p<0.001)\end{array}$} & Importance (T2-T1) & \multirow{3}{*}{0.161} & \multirow{3}{*}{0.139} & 0.289 & 3.359 & 0.001 \\
\hline & $\begin{array}{c}\text { Belief about control over the onset of } \\
\text { the disease (T2-T1) }\end{array}$ & & & -0.193 & -2.251 & 0.026 \\
\hline & Benefit (T2-T1) & & & -0.169 & -1.982 & 0.050 \\
\hline $\begin{array}{c}\text { RA: }(B=0.578 \\
F=10.829 ; p=0.002)\end{array}$ & Threat (T2-T1) & 0.139 & 0.126 & 0.373 & 3.291 & 0.002 \\
\hline \multirow{2}{*}{$\begin{array}{c}\text { VD: }(B=3.405 \\
F=8.120 ; p=0.002)\end{array}$} & $\begin{array}{l}\text { Belief regarding one's condition } \\
\text { improving (T1) }\end{array}$ & \multirow{2}{*}{0.414} & \multirow{2}{*}{0.363} & -0.656 & -3.824 & 0.001 \\
\hline & Threat (T1) & & & 0.442 & 2.580 & 0.017 \\
\hline $\begin{aligned} \mathrm{D}:(B=1.068 ; F=18.738 \\
\\
p<0.001)\end{aligned}$ & Importance (T2-T1) & 0.438 & 0.415 & 0.662 & 4.329 & 0.000 \\
\hline \multicolumn{7}{|c|}{ Satisfaction } \\
\hline \multirow{4}{*}{$\begin{array}{l}\text { All }(B=0.551 ; F=5.405 \\
\quad p<0.001)\end{array}$} & $\begin{array}{c}\text { Belief regarding the possibility of } \\
\text { predicting the course of the } \\
\text { disease (T2-T1) }\end{array}$ & \multirow{4}{*}{0.157} & \multirow{4}{*}{0.128} & 0.152 & 1.732 & 0.086 \\
\hline & $\begin{array}{c}\text { Belief about control over the onset of } \\
\text { the disease (T2-T1) }\end{array}$ & & & -0.177 & -2.043 & 0.043 \\
\hline & Female gender & & & -0.204 & -2.355 & 0.020 \\
\hline & Importance (T2-T1) & & & 0.175 & 2.004 & 0.047 \\
\hline \multirow{3}{*}{$\begin{array}{c}\mathrm{RA}(B=-3.251 \\
F=5.899 ; p<0.001)\end{array}$} & Benefit (T1) & \multirow{3}{*}{0.214} & \multirow{3}{*}{0.178} & 0.379 & 3.290 & 0.002 \\
\hline & $\begin{array}{c}\text { The belief about the duration of the } \\
\text { disease (T1) }\end{array}$ & & & 0.309 & 2.660 & 0.010 \\
\hline & Threat (T2-T1) & & & 0.260 & 2.343 & 0.022 \\
\hline \multirow[t]{2}{*}{$\begin{array}{l}\text { Vascular }(B=0.615 \\
F=18.915 ; p<0.001)\end{array}$} & $\begin{array}{l}\text { Belief regarding the possibility of } \\
\text { predicting the course of the } \\
\text { disease (T2-T1) }\end{array}$ & \multirow[t]{2}{*}{0.622} & \multirow[t]{2}{*}{0.589} & 0.715 & 5.574 & 0.000 \\
\hline & Female gender & & & -0.358 & -2.791 & 0.010 \\
\hline \multirow{3}{*}{$\begin{array}{l}\text { Diabetes }(B=-0.015 \\
F=9.963 ; p<0.001)\end{array}$} & $\begin{array}{l}\text { Belief regarding how embarrassing } \\
\text { the disease is (T1) }\end{array}$ & \multirow{3}{*}{0.576} & \multirow{3}{*}{0.518} & 0.535 & 3.850 & 0.001 \\
\hline & Number of hospitalizations & & & -0.438 & -3.094 & 0.005 \\
\hline & $\begin{array}{l}\text { Belief about control over the onset of } \\
\text { the disease (T2-T1) }\end{array}$ & & & -0.407 & -2.876 & 0.009 \\
\hline \multicolumn{7}{|c|}{ Reconcilement } \\
\hline $\begin{array}{c}\text { All }(B=0.141 \\
F=12.732 ; p<0.001)\end{array}$ & $\begin{array}{l}\text { Belief about control over the onset of } \\
\text { the disease (T2-T1) }\end{array}$ & 0.097 & 0.089 & -0.311 & -3.568 & 0.001 \\
\hline $\begin{array}{c}\mathrm{RA}(B=0.126 \\
F=14.543 ; p<0.001)\end{array}$ & Threat (T2-T1) & 0.178 & 0.166 & 0.422 & 3.814 & 0.000 \\
\hline $\begin{array}{l}\text { Vascular }(B=0.089 \\
F=4.875 ; p=0.037)\end{array}$ & $\begin{array}{l}\text { Belief about control over the onset of } \\
\text { the disease (T2-T1) }\end{array}$ & 0.169 & 0.134 & -0.411 & -2.208 & 0.037 \\
\hline $\begin{array}{l}\text { Diabetes }(B=-0.193 \\
F=12.408 ; p<0.001)\end{array}$ & $\begin{array}{l}\text { Importance (T2-T1) } \\
\text { Duration of the disease }\end{array}$ & 0.519 & 0.477 & $\begin{array}{l}0.658 \\
0.324\end{array}$ & $\begin{array}{l}4.549 \\
2.236\end{array}$ & $\begin{array}{l}0.000 \\
0.035\end{array}$ \\
\hline \multicolumn{7}{|c|}{ Distancing } \\
\hline $\begin{array}{c}\text { All }(B=-0.096 \\
F=8.361 ; p<0.001)\end{array}$ & $\begin{array}{c}\text { Importance (T2-T1) } \\
\text { Benefit (T2-T1) } \\
\text { Duration of the disease }\end{array}$ & 0.177 & 0.155 & $\begin{array}{c}0.352 \\
-0.224 \\
0.189\end{array}$ & $\begin{array}{c}4.112 \\
-2.658 \\
2.216\end{array}$ & $\begin{array}{l}0.000 \\
0.009 \\
0.029\end{array}$ \\
\hline
\end{tabular}


Table 5. Cont.

\begin{tabular}{|c|c|c|c|c|c|c|}
\hline & Statistically Significant Predictors & $\begin{array}{l}R^{2} \text { for the } \\
\text { Model }\end{array}$ & $\begin{array}{l}\text { Adjusted } R^{2} \text { for } \\
\text { the Model }\end{array}$ & $\beta$ & $t$ & $p$ \\
\hline \multirow{6}{*}{$\begin{array}{c}\mathrm{RA}(B=-2.247 \\
F=6.101 ; p<0.001)\end{array}$} & Importance (T2-T1) & \multirow{6}{*}{0.371} & \multirow{6}{*}{0.310} & 0.308 & 2.614 & 0.011 \\
\hline & Number of hospitalizations & & & -0.276 & -2.695 & 0.009 \\
\hline & Female gender & & & -0.277 & -2.694 & 0.009 \\
\hline & $\begin{array}{c}\text { Belief about knowledge about a } \\
\text { disease (T1) }\end{array}$ & & & 0.272 & 2.611 & 0.011 \\
\hline & Benefit (T1) & & & 0.247 & 2.375 & 0.021 \\
\hline & Threat (T2-T1) & & & 0.253 & 2.197 & 0.032 \\
\hline \multirow{2}{*}{$\begin{array}{c}\text { Vascular }(B=-1.480 \\
F=6.535 ; p=0.006)\end{array}$} & $\begin{array}{l}\text { Belief regarding one's condition } \\
\text { improving (T1) }\end{array}$ & \multirow{2}{*}{0.362} & \multirow{2}{*}{0.307} & -0.432 & -2.595 & 0.016 \\
\hline & Age & & & 0.417 & 2.505 & 0.020 \\
\hline Diabetes $(B=0.357$ & Importance (T2-T1) & \multirow[b]{2}{*}{0.583} & \multirow[b]{2}{*}{0.546} & 0.596 & 4.236 & 0.000 \\
\hline$F=16.051 ; p<0.001)$ & Loss (T2-T1) & & & 0.333 & 2.367 & 0.027 \\
\hline
\end{tabular}

RA-Rheumatoid arthritis; VD—Vascular diseases; D-Diabetes; T1—baseline measurement; T2—follow-up measurement.

The percentage of variance explained ranged from $8.9 \%$ (ALD-Reconcilement; all groups) to $58.9 \%$ (ALD-Satisfaction; VD group). Depending on the analyzed group, sociodemographic and clinical variables, IRBs, CAs, and changes therein were statistically significant predictors of changes in ALD. The analyses showed that changes in CAs and IRBs explained the changes in levels of ALD to a greater extent than their baseline values (T1). Change in the Importance CA was a positive predictor of: change in ALD global score in the whole group analyzed together and the diabetes group; change in ALDSatisfaction in the whole group; change in ALD-Reconcilement in diabetes; and change in ALD-Satisfaction in the whole group and the RA group. Threat was a positive predictor of change in ALD global score in the VD group. Change in threat was a positive predictor of change in ALD global score in RA patients. Change in threat was also a positive predictor of change in ALD-Satisfaction and ALD-Reconcilement in RA, and in ALD-Distancing in RA patients.

\section{Discussion}

The study focused on factors related to levels of acceptance of living with the disease (ALD) in people with rheumatoid arthritis (RA). Modifiable cognitive factors-cognitive appraisals (CAs) and illness-related beliefs (IRBs) — as well as sociodemographic variables (sex, age), and clinical factors (the duration of the disease) were assessed. We found a cubic relationship between age and ALD, and the paths between cognitive factors and levels of acceptance differed depending on the ALD subscales. Further analyses carried out on data collected after one week showed that there were statistically significant differences between the measurements in IRBs, Cas, and ALD, and that sociodemographic, clinical, and cognitive variables were responsible for changes in ALD in people who had not been treated with therapeutic interventions. We also observed statistically significant interactions between the diagnoses' predictors, which may have practical implications.

The first part of the analyses focused on determining the relationship between age and ALD. The fitted curve indicated a cubic relationship. The highest levels of ALD were observed in younger people, while levels decreased with age, flattening out and rising around the age of 70 . One explanation for this observation may be that, with age, the disease may have a negative impact on social functioning, influencing spheres of life such as work, family, and the pursuit of interests [2,36]. On one hand, people retire after 60-65 years of age, and on the other hand, they live with the disease for a longer time and might become better adapted to it. It should be noted that RA has a peak incidence around the age of 50 [15].

The next part of the analysis focused on the identification of interrelationships between modifiable cognitive factors related to levels of acceptance of living with rheumatoid arthritis. First, latent variables were determined with the use of confirmatory factor analysis, 
and then models were tested in which the relationships between these variables were fitted. To obtain the best fit, it was necessary to remove the Value and Benefit scales for CA. It is worth noting that the tested models confirmed the two-factor structure of the scale (positive CAs, i.e., value, benefit, and challenge, vs. negative ones), which had satisfactory fit parameters. However, due to the nature of the analyses and better fit parameters, a one-factor model was used for structural equation modeling (SEM), which did not contain the above two scales. Additionally, despite good fit parameters, the regression weights remained insignificant for IRB-Control, which may be due to the small sample size [37]. The next step was to test a number of models: in the case of ALD-Reconcilement and ALD-Distancing, identical paths between the analyzed variables were found; IRB-Disease had both direct and indirect (via CA) effects while IRB-Social and CA had only a direct effect on acceptance. On the other hand, for ALD-Satisfaction, the best fitted model turned out to be the one in which IRB-Disease had both direct and indirect (via CA) effects and IRB-Social had an indirect impact (via CA). It is also worth paying attention to the model fit coefficients, which had average fit. It should be noted here that the sample on which the analyses were performed was relatively small (83 observations). Hu and Bentler [38] found that in small samples it is possible that the model fit parameters might overreject the true model.

These results are important: they show that ALD is a multidimensional construct, the individual components of which are shaped on the basis of other dependencies between variables; it is not one-dimensional, as is apparent from factor analyses carried out on the acceptance of illness scale (AIS; [39]). These results can also be used in clinical practice. Based on the theoretical models of Maes et al. [24] and Leventhal et al. [25,27], it is possible to determine the relationships between IRBs and CAs, which, in the light of this research, play a very important role in the process of adaptation to life with a chronic disease. These analyses may also indicate directions for potential therapeutic interactions within, for example, cognitive behavioral therapy, which may help increase acceptance of living with RA.

The analyses also show statistically significant differences in terms of both IRBs and CA or ALD between two measurements performed one week apart. These differences can be observed both in the entire sample and in subgroups distinguished based on diagnosis. It is worth noting that the numbers for the subgroups were small, and the size of the effect may suggest that with increasing samples, the significance level could be $p<0.05$. Cognitive factors, due to their dynamic nature and sensitivity to changes occurring both in connection with the disease itself (such as exacerbation of symptoms) and environmental factors (new information, social support, etc.), may lead to changes in the indicators of adaptation to the disease. It should be emphasized that interventions are not necessary for such changes to occur-they may occur over time under the influence of many, often random, factors.

Our analyses suggest that predictors of short-term change in ALD differ across diagnoses, as well as in the cognitive factors that play an important role in this process. Difference in importance (T2-T1) as well as threat (T1 and T2-T1) were positive predictors of change in ALD for most diagnoses. Benefit contributed to lower acceptance in the case of ALDS global score and self-distancing from the disease (all diagnoses), and had a beneficial effect on satisfaction with life despite the disease and self-distancing from the disease (RA). In summary, the appraisal of the disease, even when negative, can contribute to greater acceptance. On the other hand, beliefs regarding control over the onset of the illness and its course were linked to lower levels of ALD. Beliefs concerning, inter alia, the level of one's own knowledge about the disease or its chronic nature may translate into greater acceptance.

Interactions (predictors $\times$ diagnoses) clearly showed that there were large differences between the specific diagnoses. Of particular importance to therapeutic work (e.g., cognitive behavioral therapy), is the observation that both IRBs and cognitive appraisals may have different effects on ALD depending on the diagnosis. One example is belief regarding one's condition improving (IRB 3), which is beneficial for both people with RA and D, 
but has a negative impact in the short term on the level of acceptance in people with VD. These results can be taken as an argument for greater personalization of therapy based on diagnosis and further exploration of the role of both beliefs and cognitive appraisals.

Developing knowledge about change in a short-term perspective is also particularly important: some processes, such as cognitive appraisals, are dynamic and their intensities may change over a short period of time depending on, for example, the patient's mood or events in their lives. Another argument for analyzing these processes in the short term, especially in the "natural environment", is the fact that research involving interventions aimed at modification of beliefs may affect the degree of adaptation to living with the disease not only by changing certain IRBs, but also through the therapist effect, and the changes may be related to new knowledge or experiences of other patients, as well as the therapeutic groups that provide social support. On the other hand, the results of research conducted with inpatients may be distorted due to conditions in wards (lack of privacy, or problems with sleep or adaptation to a new place), expectations regarding new treatments, separation from one's family, etc.

The results of this study also suggest that the cognitive representation of a disease is more complex and consists of more than five key beliefs [28], especially when comparing medical diagnoses with each other. The results indicate that IRBs regarding knowledge or perception of the disease by other people are statistically significant predictors of changes in ALD. In further research, it is also worth identifying and analyzing the role of diagnosisspecific IRBs due to their unique nature (for details see [40]).

For therapeutic interventions, the SEM results may be of the greatest importance, indicating that the cognitive appraisals of a disease can be modified by changing beliefs, and that both of these factors play a large role in ALD. This is especially important due to the fact that adaptation to living with the disease is constituted not only by the absence of depressive or anxiety symptoms, but also by high levels of positive indicators (see also: [41]). It is also worth emphasizing that different diagnoses have different predictors for ALD. Therefore, it is important to match specific therapeutic strategies to a given diagnosis, as this can improve short-term as well as long-term outcomes. The data can also be used in information campaigns in the form of posters/brochures or infographics distributed via social media. Such materials could better shape the beliefs of sick people, indirectly increasing the sense of acceptance. As mentioned earlier, IRBs are dynamic and may depend on many factors related to both information coming from one's environmentboth from authorities (e.g., doctors) and less reliable sources (e.g., internet forums)—but also may be related to the severity of the symptoms of the disease, the effectiveness of the treatment, and any side effects. Therefore, it is very important to support patients in developing specific ways of thinking about their own disease and the factors related to it. This is especially important for RA patients. For these people, the disease is progressive, with pain as the predominant symptom. With time, people with this diagnosis may have problems with moving around and performing daily tasks, their quality of life deteriorates, and depressive symptoms worsen; therefore, it seems necessary to foster beliefs that may increase levels of ALD.

\section{Limitations and Further Directions}

This study also has some limitations. It was conducted online, so it was not possible to medically confirm the diagnoses; however, other studies indicate a very high rate of agreement between declared and actual diagnoses (as high as 99\%; [42]). Furthermore, other clinical factors, such as the severity of the disease, were not sufficiently controlled (e.g., using DAS-28 for RA patients; [43]). Future research should consider a wider range of variables, such as, inter alia, health burdens [44,45], cognitive impairment, or economic opportunities (see also: [46]), but in the current research this was not possible due to the study procedure as well as constraints imposed by the pandemic. The results show a slight convergence between predictors in the RA group and in the overall group, which may be due to the larger size of the RA group. The study also did not analyze people with type 1 
and type 2 diabetes separately. Subsequent studies could consider both a broader repertoire of diagnoses (e.g., skin or respiratory diseases) as well as objective health status indicators (such as C-reactive protein levels in RA patients).

Another issue is the psychometric properties of the tools used: the cognitive constructs controlled in the study may change over time and depend on many factors [24]; see also Supplementary File S9 for T1 and T2-T1 correlation matrix between measured variables), some of which were beyond our control. We do not know whether the respondents experienced any deterioration in their health or what sources of information they used during the week (which is especially important for IRBs; [47]. This topic is also the subject of another publication describing the psychometric properties of the tools (in preparation). A proper solution to this problem would be a diary study in which these types of variables could be controlled; this would allow us to better identify both the dynamics of changes and possible factors that may affect them. Both the obtained results and the potential expansion of knowledge in the field of belief stability, cognitive appraisals, and factors responsible for change therein over time without the use of an intervention can also be widely used in the assessment of therapy stability (changes in cognitive factors or adaptation indicators after the end of the intervention).

\section{Conclusions}

Relationship: Our results showed a cubic relationship between age and ALD. We found that the pathways between cognitive factors and ALD differed depending on the ALD subscale. Levels of certain IRBs and CAs as well as ALD varied over the course of a week without the use of therapeutic interventions; sociodemographic and clinical factors and, primarily, IRBs and CAs were responsible for these changes in ALD. The three diagnoses examined differed in terms of the statistically significant predictors of changes in ALD. This highlights the importance of targeted interventions and suggests possible directions for them.

Supplementary Materials: The following are available online at https:/ / www.mdpi.com/article/10.3 390/ijerph19053136/s1. Supplementary File S1: Illness-Related Beliefs Scale; Supplementary File S2: Illness-Related Appraisals Scale; Supplementary File S3: CFA: IRB Disease; Supplementary File S4: CFA: IRB Social; Supplementary File S5: CFA: CA; Supplementary File S6: CFA: ALD Distancing; Supplementary File S7: CFA: ALD Reconcilement; Supplementary File S8: CFA: ALD Satisfaction; Supplementary File S9: T1-T2 and T1 correlation matrix; Supplementary File S10: Differences between T1 and T2 in subgroups distinguished by diagnosis; Supplementary File S11: Acceptance Global Score and subscales: interactions between predictors; Supplementary File S12: ALD (T2-T1): interactions between predictors; Supplementary File S13: ALD Reconcilement (T2-T1): interactions between predictors; Supplementary File S14: ALD Satisfaction (T2-T1): interactions between predictors; Supplementary File S15: ALD Self-distancing (T2-T1): interactions between predictors.

Author Contributions: D.P.: conceptualization, methodology, formal analysis, investigation, resources, data curation, writing - original draft, writing - review and editing, visualization, supervision, project administration, funding acquisition. K.W.-P.: investigation, visualization, writingreview and editing, funding acquisition. E.P.: writing - review and editing, funding acquisition. A.F.: writing-review and editing, funding acquisition. B.K.: writing-review and editing. E.K.: writing - review and editing. W.T.: writing - review and editing. All authors have read and agreed to the published version of the manuscript.

Funding: This work was supported by the Faculty of Psychology, University of Warsaw, from the funds awarded by the Ministry of Science and Higher Education in the form of a subsidy for the maintenance and development of research potential in 2021 (501-D125-01-1250000 zlec*. 5011000221), University of Economics and Human Sciences and Cardinal Wyszýnski University own funds. Article Processing Charge was covered by funds from IDUB (Excellence Initiative-Research University; University of Warsaw), University of Economics and Human Sciences in Warsaw and Polish Society of Public Health own funds. 
Institutional Review Board Statement: Approval from the local Institutional Ethical Committee at the first author's University was obtained for this study. Informed consent was obtained from all participants upon enrollment.

Informed Consent Statement: Consent for publication was obtained along with the consent to participate in this study.

Data Availability Statement: The data as well as R code that support the findings of this study will be available after publication at the OSF project page.

Conflicts of Interest: The authors declare no conflict of interest.

\section{References}

1. Hajat, C.; Stein, E. The global burden of multiple chronic conditions: A narrative review. Prev. Med. Rep. 2018, 12, 284-293. [CrossRef] [PubMed]

2. Scharn, M.; Hengel, K.O.; Boot, C.R.L.; Burdorf, A.; Schuring, M.; Van Der Beek, A.J.; Robroek, S.J.W. Influence of chronic diseases on societal participation in paid work, volunteering and informal caregiving in Europe: A 12-year follow-up study. J. Epidemiol. Community Health 2018, 73, 136-141. [CrossRef] [PubMed]

3. Birk, J.L.; Kronish, I.M.; Moise, N.; Falzon, L.; Yoon, S.; Davidson, K.W. Depression and multimorbidity: Considering temporal characteristics of the associations between depression and multiple chronic diseases. Health Psychol. 2019, 38, 802-811. [CrossRef] [PubMed]

4. Lotfaliany, M.; Bowe, S.J.; Kowal, P.; Orellana, L.; Berk, M.; Mohebbi, M. Depression and chronic diseases: Co-occurrence and communality of risk factors. J. Affect. Disord. 2018, 241, 461-468. [CrossRef]

5. de Ridder, D.; Geenen, R.; Kuijer, R.; van Middendorp, H. Psychological adjustment to chronic disease. Lancet 2008, 372, $246-255$. [CrossRef]

6. $\quad$ Beşirli, A.; Alptekin, J.Ö.; Kaymak, D.; Özer, Ö.A. The Relationship Between Anxiety, Depression, Suicidal Ideation and Quality of Life in Patients with Rheumatoid Arthritis. Psychiatr. Q. 2020, 91, 53-64. [CrossRef]

7. Jang, S.M.; Kim, K.U.; Na, H.J.; Song, S.E.; Lee, S.H.; Lee, H.; Kim, Y.S.; Lee, M.K.; Park, H.-K. Depression is a major determinant of both disease-specific and generic health-related quality of life in people with severe COPD. Chronic Respir. Dis. 2018, 16, 1-8. [CrossRef]

8. Turan, B.; Rice, W.; Crockett, K.B.; Johnson, M.; Neilands, T.B.; Ross, S.N.; Kempf, M.-C.; Konkle-Parker, D.; Wingood, G.; Tien, P.C.; et al. Longitudinal association between internalized HIV stigma and antiretroviral therapy adherence for women living with HIV. AIDS 2019, 33, 571-576. [CrossRef]

9. Obiegło, M.; Siennicka, A.; Jankowska, E.A.; Danel, D.P. Direction of the Relationship Between Acceptance of Illness and Health-Related Quality of Life in Chronic Heart Failure Patients. J. Cardiovasc. Nurs. 2017, 32, 348-356. [CrossRef]

10. Bien, A.; Rzońca, E.; Kańczugowska, A.; Iwanowicz-Palus, G. Factors Affecting the Quality of Life and the Illness Acceptance of Pregnant Women with Diabetes. Int. J. Environ. Res. Public Health 2015, 13, 68. [CrossRef]

11. Guzek, Z.; Kowalska, J. Analysis of the Degree of Acceptance of Illness Among Patients After a Stroke: An Observational Study. Clin. Interv. Aging 2020, 15, 2063-2072. [CrossRef] [PubMed]

12. Bąk, E.; Marcisz, C.; Krzemińska, S.; Dobrzyn-Matusiak, D.; Foltyn, A.; Drosdzol-Cop, A. Relationships of Sexual Dysfunction with Depression and Acceptance of Illness in Women and Men with Type 2 Diabetes Mellitus. Int. J. Environ. Res. Public Health 2017, 14, 1073. [CrossRef] [PubMed]

13. Janowski, K.; Steuden, S.; Kuryłowicz, J. Factors accounting for psychosocial functioning in patients with low back pain. Eur. Spine J. 2009, 19, 613-623. [CrossRef]

14. Paloș, R.; Vîșcu, L. Anxiety, Automatic Negative Thoughts, and Unconditional Self-Acceptance in Rheumatoid Arthritis: A Preliminary Study. Int. Sch. Res. Not. 2014, 2014, 317259. [CrossRef] [PubMed]

15. van der Woude, D.; Mil, A.H.V.D.H.-V. Update on the epidemiology, risk factors, and disease outcomes of rheumatoid arthritis. Best Pr. Res. Clin. Rheumatol. 2018, 32, 174-187. [CrossRef] [PubMed]

16. Scott, D.L.; Steer, S. The course of established rheumatoid arthritis. Best Pr. Res. Clin. Rheumatol. 2007, 21, 943-967. [CrossRef]

17. Welsing, P.M.J.; Fransen, J.; van Riel, P.L.C.M. Is the disease course of rheumatoid arthritis becoming milder?: Time trends since 1985 in an inception cohort of early rheumatoid arthritis. Arthritis Care Res. 2005, 52, 2616-2624. [CrossRef]

18. Zhou, Y.; Wang, X.; An, Y.; Zhang, X.; Han, S.; Li, X.; Wang, L.; Wang, C.; Wang, Y.; Yang, R. Disability and health-related quality of life in Chinese patients with rheumatoid arthritis: A cross-sectional study. Int. J. Rheum. Dis. 2018, 21, 1709-1715. [CrossRef]

19. Pu, D.; Luo, J.; Wang, Y.; Ju, B.; Lv, X.; Fan, P.; He, L. Prevalence of depression and anxiety in rheumatoid arthritis patients and their associations with serum vitamin D level. Clin. Rheumatol. 2018, 37, 179-184. [CrossRef]

20. Machin, A.R.; Babatunde, O.; Haththotuwa, R.; Scott, I.; Blagojevic-Bucknall, M.; Corp, N.; Chew-Graham, C.A.; Hider, S.L. The association between anxiety and disease activity and quality of life in rheumatoid arthritis: A systematic review and meta-analysis. Clin. Rheumatol. 2020, 39, 1471-1482. [CrossRef] 
21. Berner, C.; Erlacher, L.; Fenzl, K.H.; Dorner, T.E. A cross-sectional study on self-reported physical and mental health-related quality of life in rheumatoid arthritis and the role of illness perception. Health Qual. Life Outcomes 2018, 16, 238. [CrossRef] [PubMed]

22. Liu, L.; Xu, N.; Wang, L. Moderating role of self-efficacy on the associations of social support with depressive and anxiety symptoms in Chinese patients with rheumatoid arthritis. Neuropsychiatr. Dis. Treat. 2017, 13, 2141-2150. [CrossRef] [PubMed]

23. Kostova, Z.; Caiata-Zufferey, M.; Schulz, P.J. The process of acceptance among rheumatoid arthritis patients in Switzerland: A qualitative study. Pain Res. Manag. 2014, 19, 61-68. [CrossRef]

24. Maes, S.; Leventhal, H.; de Ridder, D.T. Coping with chronic diseases. In Handbook of Coping: Theory, Research, Applications; Zeidner, M., Endler, N.S., Eds.; John Wiley: Hoboken, NJ, USA, 1996; pp. 221-251.

25. Leventhal, H.; Meyer, D.; Nerenz, D. The common sense representation of illness danger. In Contributions to Medical Psychology; Rachman, S., Ed.; Psychology Press: Hove, UK, 1980; Volume 2, pp. 7-30.

26. Lazarus, R.S.; Folkman, S. Stress, Appraisal and Coping, 1st ed.; Springer: Berlin/Heidelberg, Germany, 1984.

27. Leventhal, H.; Phillips, L.A.; Burns, E. The Common-Sense Model of Self-Regulation (CSM): A dynamic framework for understanding illness self-management. J. Behav. Med. 2016, 39, 935-946. [CrossRef] [PubMed]

28. Weinman, J.; Petrie, K.J.; Moss-Morris, R.; Horne, R. The illness perception questionnaire: A new method for assessing the cognitive representation of illness. Psychol. Health 1996, 11, 431-445. [CrossRef]

29. Groeneveld, I.; van der Pas, S.; Meesters, J.; Schuurman, J.; van Meijeren-Pont, W.; Jagersma, E.; Goossens, P.; Kaptein, A.; Vlieland, T.V. Illness perceptions of stroke survivors: Predictors and changes over time-A 1 year follow-up study. J. Psychosom. Res. 2019, 116, 54-61. [CrossRef] [PubMed]

30. Tsay, S.-L. Self-efficacy training for patients with end-stage renal disease. J. Adv. Nurs. 2003, 43, 370-375. [CrossRef]

31. Cooper, V.; Gellaitry, G.; Hankins, M.; Fisher, M.; Horne, R. The influence of symptom experiences and attributions on adherence to highly active anti-retroviral therapy (HAART): A six-month prospective, follow-up study. AIDS Care 2009, 21, 520-528. [CrossRef]

32. Pankowski, D.; Wytrychiewicz, K.; Janowski, K. Illness-Related Beliefs Scale. 2021. Available online: https://doi.org/10.17605 /OSF.IO/JCP2U (accessed on 22 February 2022). [CrossRef]

33. Pankowski, D.; Wytrychiewicz, K.; Janowski, K. Illness-Related Appraisal Scale. 2021. Available online: https://doi.org/10.17605 /OSF.IO/BYAXS (accessed on 18 February 2022). [CrossRef]

34. Janowski, K.; Steuden, S.; Pietrzak, A.; Krasowska, D.; Kaczmarek, Łukasz; Gradus, I.; Chodorowska, G. Social support and adaptation to the disease in men and women with psoriasis. Arch. Dermatol. Res. 2012, 304, 421-432. [CrossRef]

35. Long, J. Analysis and Presentation of Social Scientific Data. 2021. Available online: https://CRAN.R-project.org/package=jtools (accessed on 7 January 2022).

36. Theis, K.A.; Roblin, D.W.; Helmick, C.G.; Luo, R. Prevalence and causes of work disability among working-age U.S. adults, 2011-2013, NHIS. Disabil. Health J. 2018, 11, 108-115. [CrossRef]

37. Wolf, E.J.; Harrington, K.M.; Clark, S.L.; Miller, M.W. Sample size requirements for structural equation models: An evaluation of power, bias, and solution propriety. Educ. Psychol. Meas. 2013, 73, 913-934. [CrossRef] [PubMed]

38. Hu, L.-T.; Bentler, P.M. Cutoff criteria for fit indexes in covariance structure analysis: Conventional criteria versus new alternatives Struct. Equ. Model. Multidiscip. J. 1999, 6, 1-55. [CrossRef]

39. Soliman, M.M. Arabic Translation and Validation of the Acceptance of Illness Scale and Person-Centered Dermatology Self-care Index. Adv. Ski. Wound Care 2021, 34, 1-8. [CrossRef] [PubMed]

40. Wytrychiewicz, K.; Pankowski, D.; Janowski, K.; Benoit, C.E.; Bargiel-Matusiewicz, K.; Pisula, E.; Walicka, M. The role of beliefs about the impact of illness on fertility and close relationships for psychopathological symptoms in women treated for hypothyroidism. J. Clin. Psychol. 2020, 76, 2314-2328. [CrossRef]

41. Seligman, M.E.P. Positive Health. Appl. Psychol. 2008, 57, 3-18. [CrossRef]

42. D'Aloisio, A.A.; Nichols, H.B.; Hodgson, M.E.; Deming-Halverson, S.L.; Sandler, D.P. Validity of self-reported breast cancer characteristics in a nationwide cohort of women with a family history of breast cancer. BMC Cancer 2017, 17, 692. [CrossRef]

43. Leeb, B.F.; Andel, I.; Sautner, J.; Bogdan, M.; Maktari, A.; Nothnagl, T.; Rintelen, B. Disease activity measurement of rheumatoid arthritis: Comparison of the simplified disease activity index (SDAI) and the disease activity score including 28 joints (DAS28) in daily routine. Arthritis Care Res. 2005, 53, 56-60. [CrossRef]

44. Tackling the Burden of Chronic Diseases in the USA. Lancet 2009, 373, 185. Available online: http://www.thelancet.com/journals/ lancet/article/PIIS0140-6736(09)60048-9/fulltext (accessed on 15 January 2022). [CrossRef]

45. Raghupathi, W.; Raghupathi, V. An Empirical Study of Chronic Diseases in the United States: A Visual Analytics Approach to Public Health. Int. J. Environ. Res. Public Health 2018, 15, 431. [CrossRef]

46. Maresova, P.; Javanmardi, E.; Barakovic, S.; Husic, J.B.; Tomsone, S.; Krejcar, O.; Kuca, K. Consequences of chronic diseases and other limitations associated with old age-A scoping review. BMC Public Health 2019, 19, S170-S182. [CrossRef]

47. Benyamini, Y. Health and illness perceptions. In The Oxford Handbook of Health Psychology; Friedman, H.S., Ed.; Oxford University Press: Oxford, UK, 2011; pp. 281-314. 